\title{
The Influence of Slide-Roll Ratio on ZDDP Tribofilm Formation
}

\author{
Yasunori Shimizu $^{1,2} \cdot$ Hugh A. Spikes ${ }^{1}$
}

Received: 30 June 2016/Accepted: 30 July 2016/Published online: 16 September 2016

(C) The Author(s) 2016. This article is published with open access at Springerlink.com

\begin{abstract}
The anti-wear performance and action mechanisms of zinc dithiophosphate (ZDDP) have been investigated under various test conditions. The Mini Traction Machine-Space Layer Imaging (MTM-SLIM) is a widely used and useful method for monitoring tribofilm formation by ZDDPs. However, tests are generally carried out in mixed sliding-rolling conditions, typically between $50 \%$ SRR (slide-roll ratio) and $100 \%$ SRR. In this paper, the authors describe an investigation of ZDDP film formation at SRRs much higher than $100 \%$ SRR, including pure sliding conditions using a novel MTM-SLIM technique. At high SRRs, ZDDP tribofilms form without damaging the ball surfaces so long as both surfaces move above a threshold speed with respect to the contact, regardless of whether the two surfaces move in the same or opposing directions. In pure sliding conditions, although the worn area expands with time under pure sliding conditions showing that wear takes place, tribofilms are still built up throughout a test and the ZDDP has a beneficial effect on wear rate. The very early stages of film formation are studied to show that a tribofilm with a high concentration of $\mathrm{S}$ is formed initially and then replaced with a film having a high concentration of $\mathrm{Zn}$ and $\mathrm{P}$.
\end{abstract}

Yasunori Shimizu

yasunori.shimizu@idemitsu.com

1 Tribology Group, Department of Mechanical Engineering, Imperial College London, South Kensington, Exhibition Road, London SW7 2AZ, UK

2 Lubricants Research Laboratory, Idemitsu Kosan Co., Ltd, 24-4, Anesakikaigan, Ichihara-Shi, Chiba 299-0107, Japan
Keywords Zinc dithiophosphate - ZDDP · ZnDTP . Tribofilm $\cdot$ Wear $\cdot$ Anti-wear Pure sliding conditions . MTM · SLIM

\section{Introduction}

Zinc dialkyldithiophosphates (ZDDPs) are used in engine oils, primarily as anti-wear additives. Many studies on the mechanisms of ZDDP's anti-wear and anti-seizure performance have been carried out under pure sliding conditions using friction machines such as the Shell four-ball, Falex block-on-ring, Optimol SRV and Cameron Print reciprocating rig. In these researches, after rubbing tests the physical and chemical properties of ZDDP tribofilms have been investigated using surface characterisation methods such as atomic force microscopy (AFM), scanning electron microscopy (SEM), Energy-dispersive X-ray spectroscopy (EDX) and X-ray absorption near-edge structure (XANES) [1-7].

The Mini Traction Machine-Space Layer Imaging, PCS Instrument (MTM-SLIM) is a well-known and useful method to investigate anti-wear performance and monitor ZDDP tribofilm growth in situ, and the kinetics of ZDDP tribofilm growth under various conditions have been reported [8-17]. Such tests are currently carried out in mixed sliding-rolling, typically between $50 \%$ SRR (slideroll ratio) and $100 \%$ SRR, but engine oils are also required to show good anti-wear performance at higher SRRs and especially in pure sliding such as in the piston ring and cylinder liner assembly. The influence of higher values of SRR on ZDDP film formation is rarely investigated.

In this paper, the influence of SRR on ZDDP tribofilm formation has been studied when SRR is considerably higher than $100 \%$ SRR. SRR is defined as the ratio of the sliding speed to the mean rolling speed. 
$\mathrm{SRR}=\left|u_{\mathrm{D}}-u_{\mathrm{B}}\right| / U$

where $u_{\mathrm{B}}$ and $u_{\mathrm{D}}$ are the speeds of the ball and disc surfaces relative to the contact and $U$ is the entrainment or mean speed, $\left(u_{\mathrm{B}}+u_{\mathrm{D}}\right) / 2$. When ball and disc rotate at the same surface speed in the same direction, contact conditions are "pure rolling", and when one of the surfaces is stationary, SRR is $200 \%$ and this situation is generally termed "pure sliding". This is something of a misnomer since "pure sliding" should actually be the case when the mean rolling speed is zero; i.e. the surfaces move at equal and opposite speeds with respect to the contact. However, in this paper, normal practice is followed of using the term "pure sliding" to mean one surface stationary. In all other cases, when both ball and disc rotate at different speeds with respect to the contact mixed sliding-rolling conditions prevail. In this study, a new approach developed by the authors that enables ZDDP tribofilm formation to be monitored in pure sliding conditions using MTM-SLIM is described.

\section{Test Methods}

The experiments in this work are conducted in a MTMSLIM ball on disc test rig as shown in detail in Fig. 1a. A 19.05-mm-diameter ball made of AISI 52100 $\left(R_{\mathrm{a}}=0.02 \mu \mathrm{m}\right)$ is loaded against a flat surface of a 48-mm-diameter steel disc (AISI 52100, $R_{\mathrm{a}}=0.01 \mu \mathrm{m}$ ) which is immersed in the oil sample. The ball and the disc are continuously rotated by separate electric motors, and tribofilms form on both rubbing surfaces. At set intervals, the rotation is halted and the ball is raised and loaded upward against a coated glass window (Fig. 1b). An interference image of the contact between the ball and the glass window is captured by a camera in order to record the film formation on the ball.

In mixed sliding-rolling conditions, the ball and disc are simultaneously rotated at different speeds. Since tribofilm forms all around the ball, when the ball is loaded against the SLIM window, the rubbed track is pressed against the disc (Fig. 2a). However, in pure sliding conditions, tribofilm forms only on the point contact area because the ball is fixed (Fig. 2b). Therefore, in order to measure the tribofilm formed on the ball, it is necessary to rotate the ball shaft by $180^{\circ}$ prior to image capture. This is shown schematically in Fig. 2 and is a new technique developed by the authors.

\section{Test Conditions}

Table 1 shows the main test conditions used for mixed sliding-rolling tests in this study. The load, the mean speed and the oil temperature were kept constant during all tests,

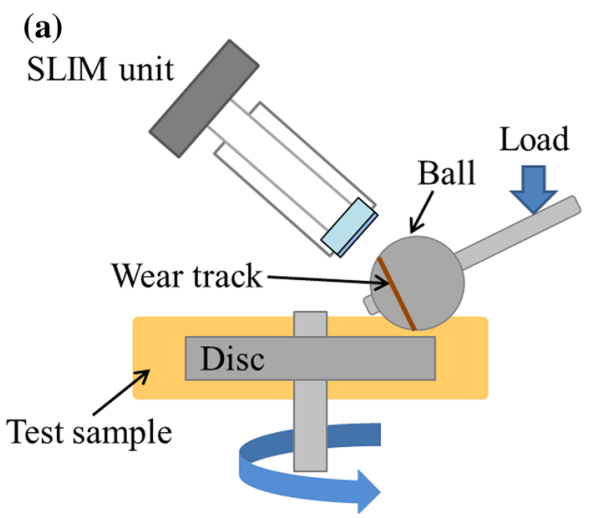

(b)

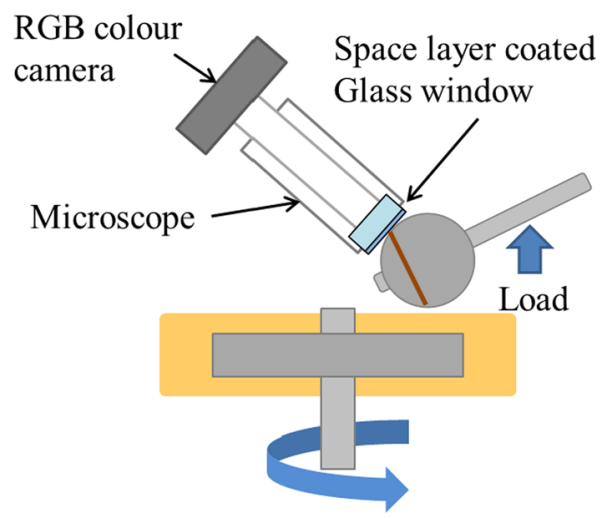

Fig. 1 a Schematic image of MTM-SLIM during a friction test. b Schematic image of MTM-SLIM while capturing an image
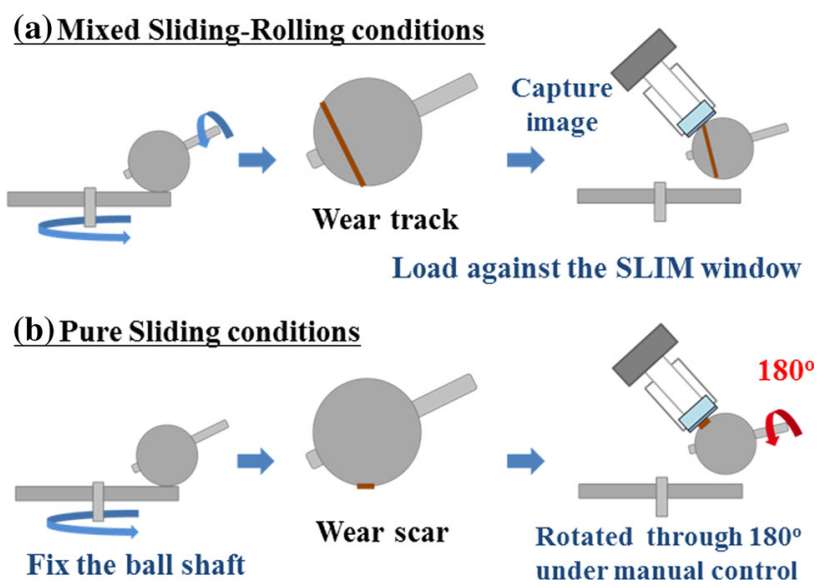

Fig. 2 Difference in the test methods between mixed sliding-rolling and pure sliding conditions

at $20 \mathrm{~N}$ (maximum Hertzian pressure $P_{\max }=0.82 \mathrm{GPa}$ ), $160 \mathrm{~mm} / \mathrm{s}$ and $130{ }^{\circ} \mathrm{C}$, respectively. The SRR conditions were varied from 50 SRR to $230 \%$ SRR, where SRR is defined by Eq. 1 . When the SRR is $<200 \%$, tests are performed under mixed rolling-sliding conditions with the ball and the disc rotating in the same direction (co-rotating mixed sliding-rolling). SRR of $200 \%$ corresponds to pure 
Table 1 Test conditions under mixed sliding-rolling conditions

\begin{tabular}{|c|c|c|c|c|c|c|c|c|c|}
\hline Load $(N)$ & \multicolumn{9}{|c|}{$20\left(P_{\max }=0.82 \mathrm{Gpa}\right)$} \\
\hline $\operatorname{SRR}(\%)$ & 50 & 100 & 198 & 199 & 200 & 201 & 202 & 205 & 230 \\
\hline Ball speed $(\mathrm{mm} / \mathrm{s})$ & 120.0 & 80.0 & 1.6 & 0.8 & 0.0 & -0.8 & -1.6 & -4.0 & -24.0 \\
\hline Disc speed $(\mathrm{mm} / \mathrm{s})$ & 200.0 & 240.0 & 318.4 & 319.2 & 320.0 & 320.8 & 321.6 & 324.0 & 344.0 \\
\hline Mean speed $(\mathrm{mm} / \mathrm{s})$ & \multicolumn{9}{|c|}{ Always 160} \\
\hline Temperature $\left({ }^{\circ} \mathrm{C}\right)$ & \multicolumn{9}{|c|}{ Always 130} \\
\hline
\end{tabular}

Table 2 Test conditions under pure sliding conditions

\begin{tabular}{|c|c|c|c|}
\hline Load $(N)$ & \multicolumn{3}{|c|}{$20\left(P_{\max }=0.82 \mathrm{Gpa}\right)$} \\
\hline $\operatorname{SRR}(\%)$ & 200 & & \\
\hline Ball speed $(\mathrm{mm} / \mathrm{s})$ & 0.0 & & \\
\hline Disc speed $(\mathrm{mm} / \mathrm{s})$ & 320.0 & & \\
\hline Mean speed $(\mathrm{mm} / \mathrm{s})$ & 160 & & \\
\hline Temperature $\left({ }^{\circ} \mathrm{C}\right)$ & 40 & 100 & 130 \\
\hline
\end{tabular}

sliding condition with the ball stationary. For more than the $200 \%$ SRR, mixed rolling-sliding conditions are reached again. As opposed to SRRs lower than $200 \%$, above $200 \%$ the ball and the disc are rotating in opposite directions (contra-rotating mixed sliding-rolling).

Table 2 shows the conditions under pure sliding tests in this study. The oil temperature was set at 40, 80, 100, $130{ }^{\circ} \mathrm{C}$. The load and the mean speed were kept constant during all tests and set at the same value as the ones under mixed sliding-rolling conditions; $20 \mathrm{~N}\left(P_{\max }=0.82\right.$ GPa), $160 \mathrm{~mm} / \mathrm{s}$.

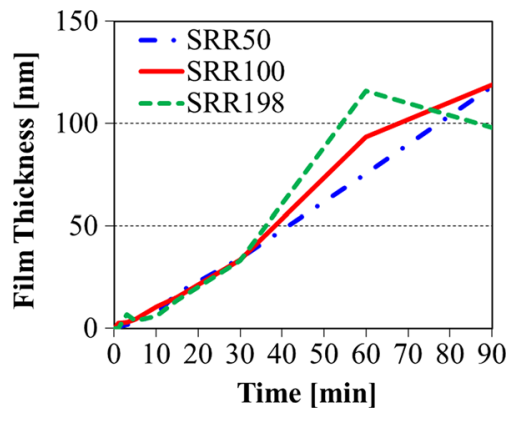

Fig. 4 Mean film thickness on the ball at different SRRs

\section{Test Samples}

In both mixed sliding-rolling conditions, all test samples were solutions of a ZDDP in polyalphaolefin base oil at a concentration that corresponds to $0.08 \mathrm{wt} \%$ of phosphorus, with no other additives present. The ZDDP employed was a C8 primary type, and the base oil had a kinetic viscosity of $4.1 \mathrm{~mm}^{2} / \mathrm{s}$ at $100{ }^{\circ} \mathrm{C}$ and a VI of 124 . In pure sliding conditions, an organo-disulphide additive and a sulphurfree zinc alkyl phosphate additive, both additives having

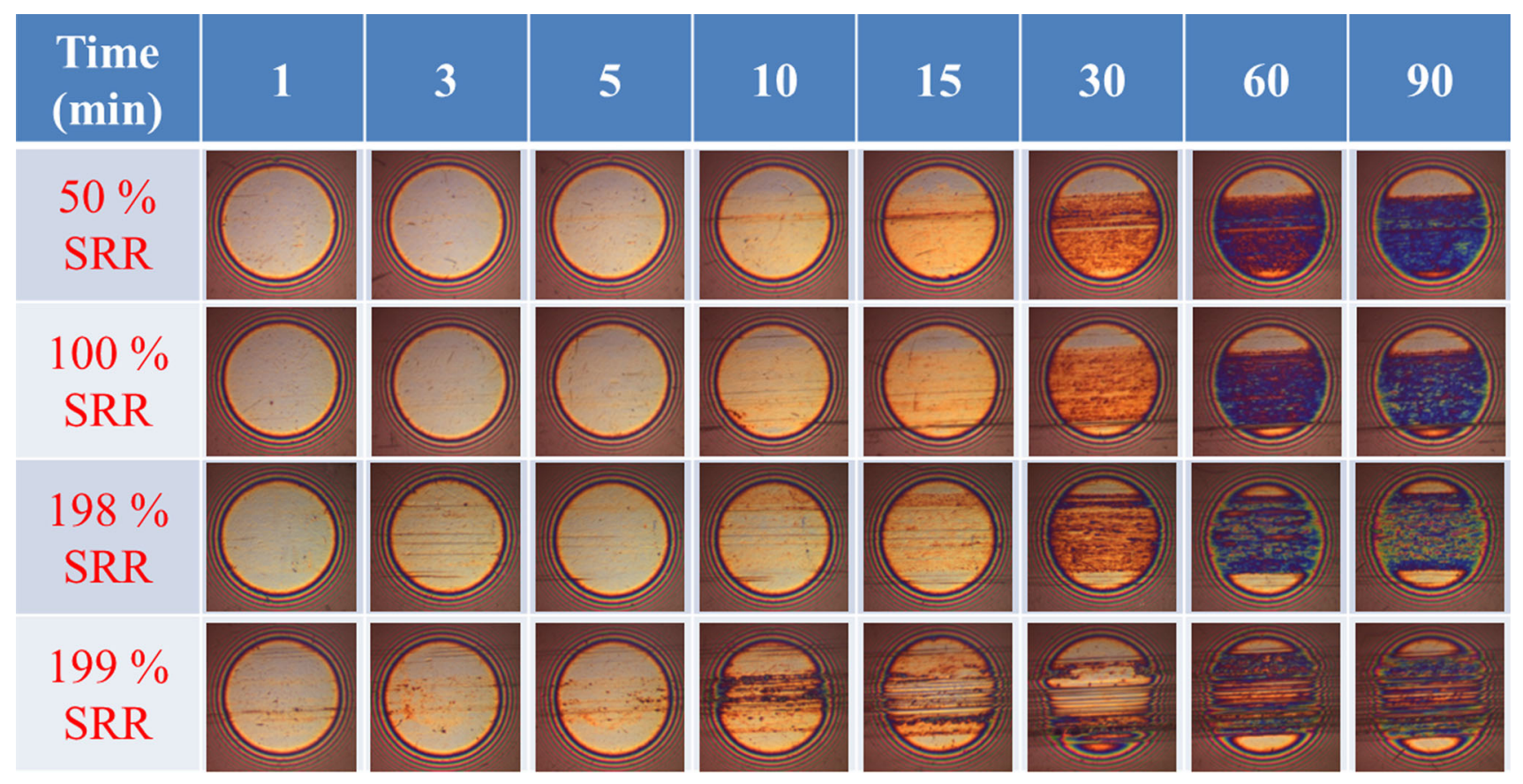

Fig. 3 Series of interference images of the wear scar on the ball during growth of tribofilm under co-rotating mixed sliding-rolling conditions 


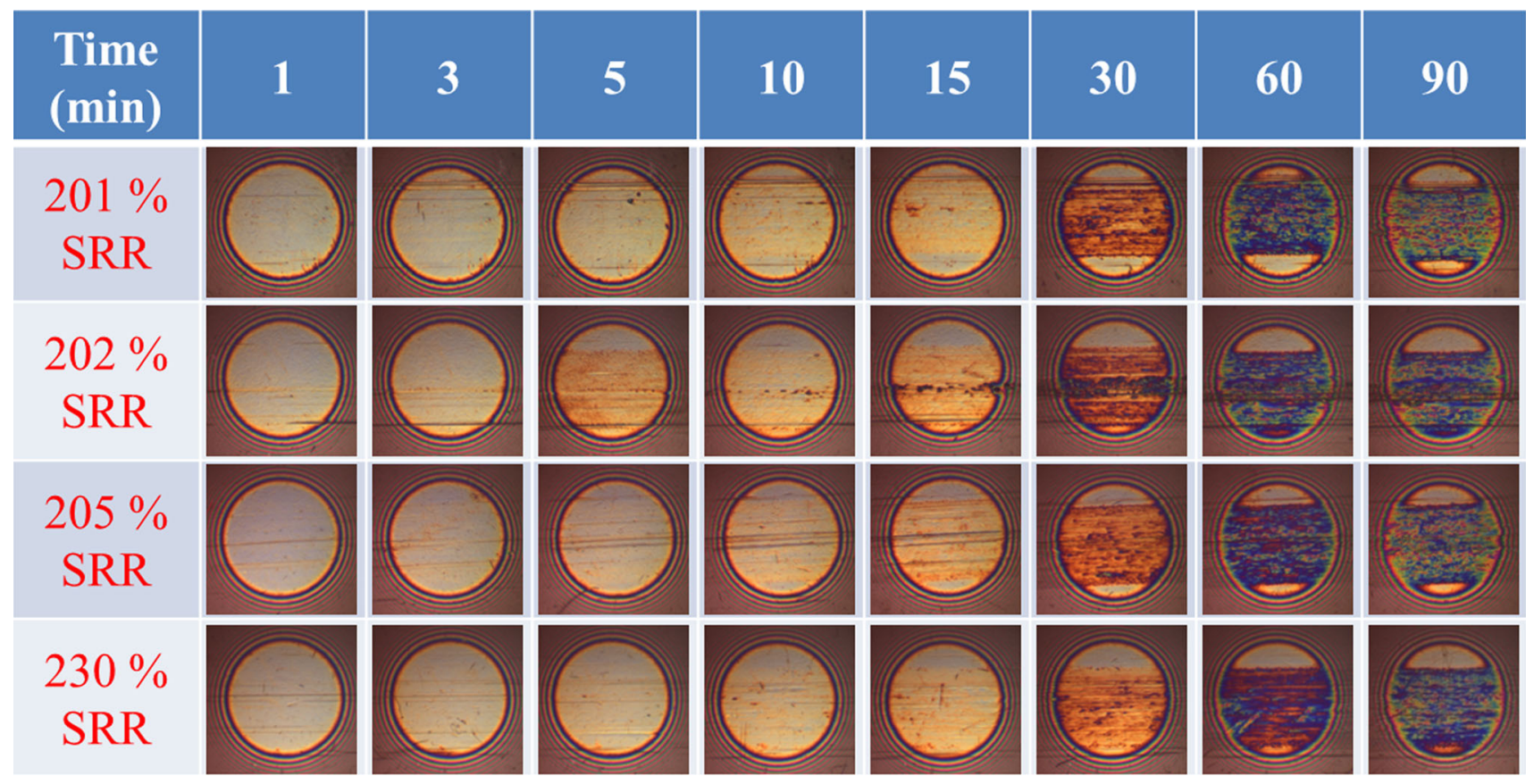

Fig. 5 Series of SLIM images of the ball contra-rotating conditions

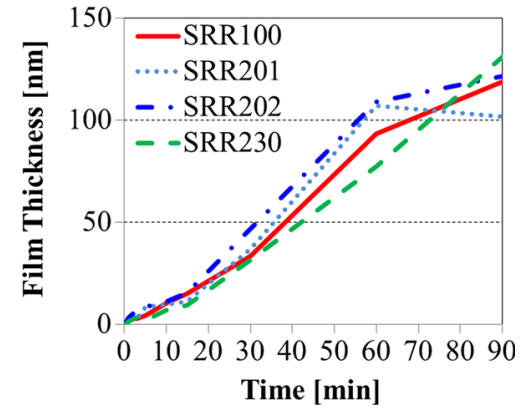

Fig. 6 Film thickness on the ball during contra-rotating conditions

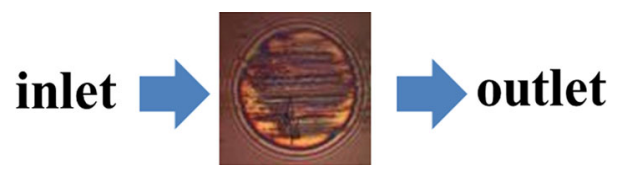

Fig. 7 Flow direction of oil lubricant
C8 alkyl chains, were also employed in order to compare with the tribofilm forming properties of the ZDDP. These additives were used at concentrations corresponding to $0.15 \mathrm{wt} \%$ of sulphur or $0.08 \mathrm{wt} \%$ of phosphorus.

\section{Test Results}

\subsection{Influence of Slide-Roll Ratio Under Mixed Sliding and Rolling Conditions}

The film-forming properties of ZDDP were studied at the different SRRs. Figure 3 shows interference images captured by MTM-SLIM, and Fig. 4 shows mean film thicknesses on the balls which were calculated from these interference images.

At 50 and $100 \%$ SRR, which are conditions used in most previous studies, it can be seen that the colour of the images gradually changes with rubbing time. This indicates

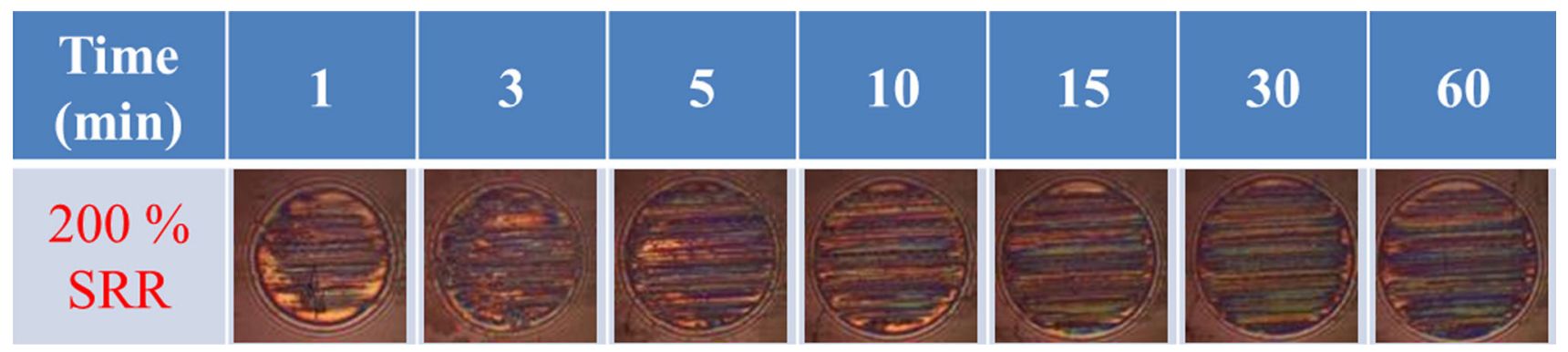

Fig. 8 Series of SLIM images of the ball in pure sliding conditions (ZDDP oil) 


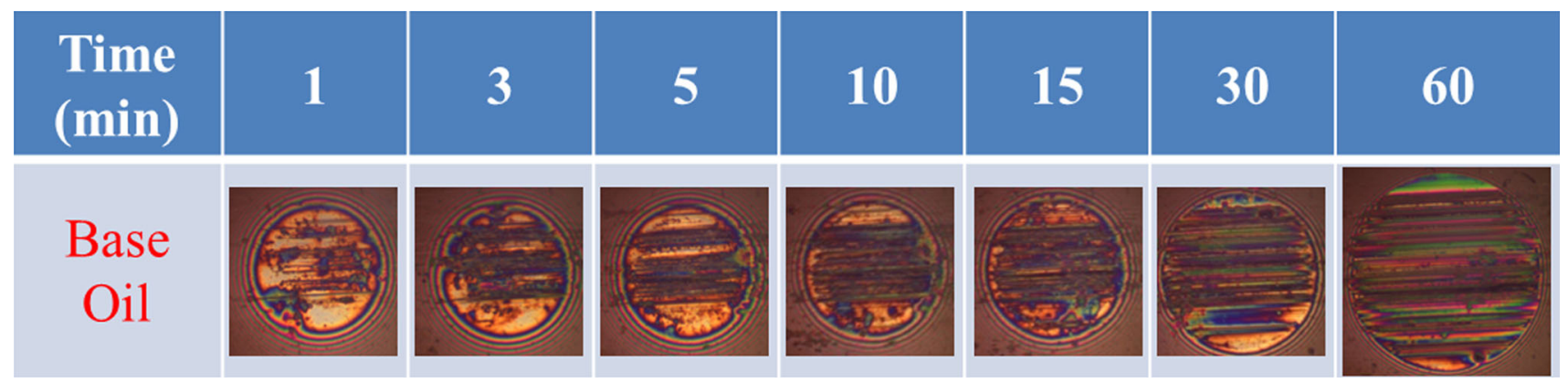

Fig. 9 Series of SLIM images of the ball in pure sliding conditions (base oil)

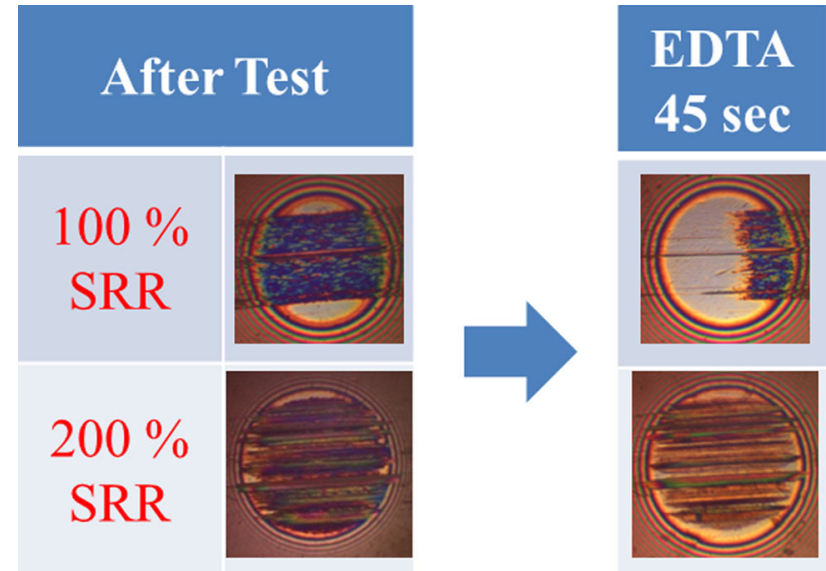

Fig. 10 SLIM images of the anti-wear films removed with EDTA that ZDDP tribofilms are formed on the rubbed tracks on the MTM balls and that they build up during rubbing. The mean ZDDP film thickness rapidly reaches $100 \mathrm{~nm}$. At $198 \%$ SRR, a thick ZDDP tribofilm is also formed rapidly on the ball surfaces to reach a thickness of ca $100 \mathrm{~nm}$. No wear scars, as evidenced by irregularities in the circular interference image of the ball pressed against the glass window or changes in its diameter, were observed on the surface. No significant differences in the colour of these images were detected even though the sliding distances were different. At $199 \%$ SRR, some wear occurred but tribofilms were still built up in the proximity of the worn area preventing the wear from progressing. Importantly, the images indicate that no tribofilm was observable inside the worn area-the central strip of the images at $199 \%$ in Fig. 3.

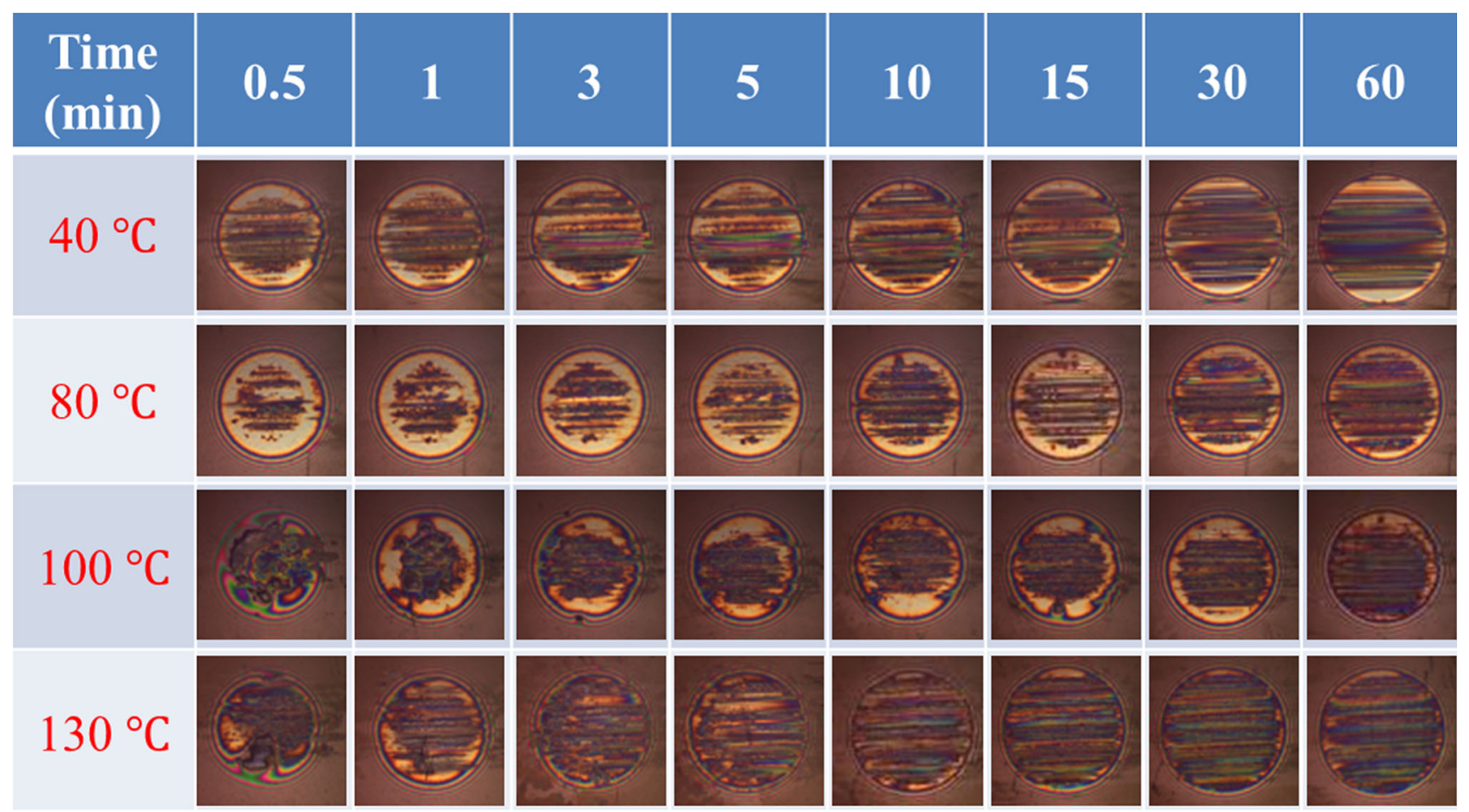

Fig. 11 Series of SLIM images of the ball in pure sliding at various temperatures 
SRR values above $200 \%$ (contra-rotating mixed sliding-rolling) are nominally more severe test conditions than those below $200 \%$ SRR (co-rotating mixed sliding-

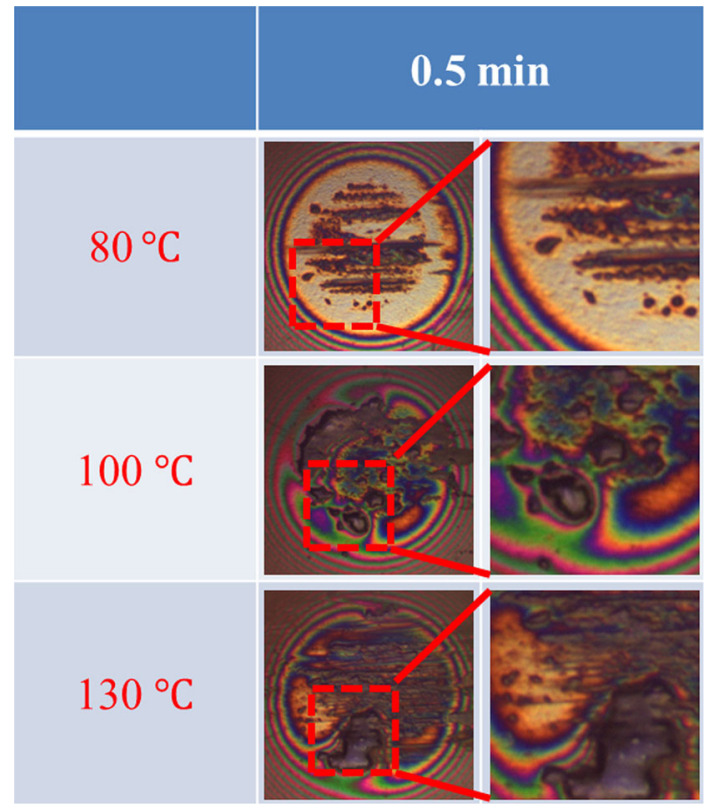

Fig. 12 Particles on the ball after $0.5 \mathrm{~min}$ rolling) due to the fact that the ball and the disc are rotating in opposite directions. Although some brown particles were observed on the surface after $15 \mathrm{~min}$ at $202 \%$ SRR and some light wear scars were observed from 10 to $15 \mathrm{~min}$ at $205 \%$ SRR, no significant damage was recorded from 201 to $205 \%$ SRR (Fig. 5) and the growth rates of the tribofilm recorded for these test conditions were similar to that observed at $100 \%$ SRR (Fig. 6).

For all test conditions where tribofilm was able to form on the ball surface, the rate of film formation was similar, irrespective of SRR. The fact that the rate of film build-up is independent of the sliding distance and only dependent on the test time (or the fraction of the test time during which any part of the ball track is in contact) is consistent with a recently proposal that ZDDP film formation is controlled by shear stress according to a stress-promoted thermal activation model [18]. In this model, when a shear stress is present, the activation energy controlling ZDDP reaction is reduced by a factor proportional to this stress, so the rate of reaction increases exponentially with applied shear stress. Since the shear stress at asperity contact is only very weakly dependent on sliding speed, the ZDDP tribofilm film build-up is independent of the SRR and depends only on how long the surface is subject to the shear stress.

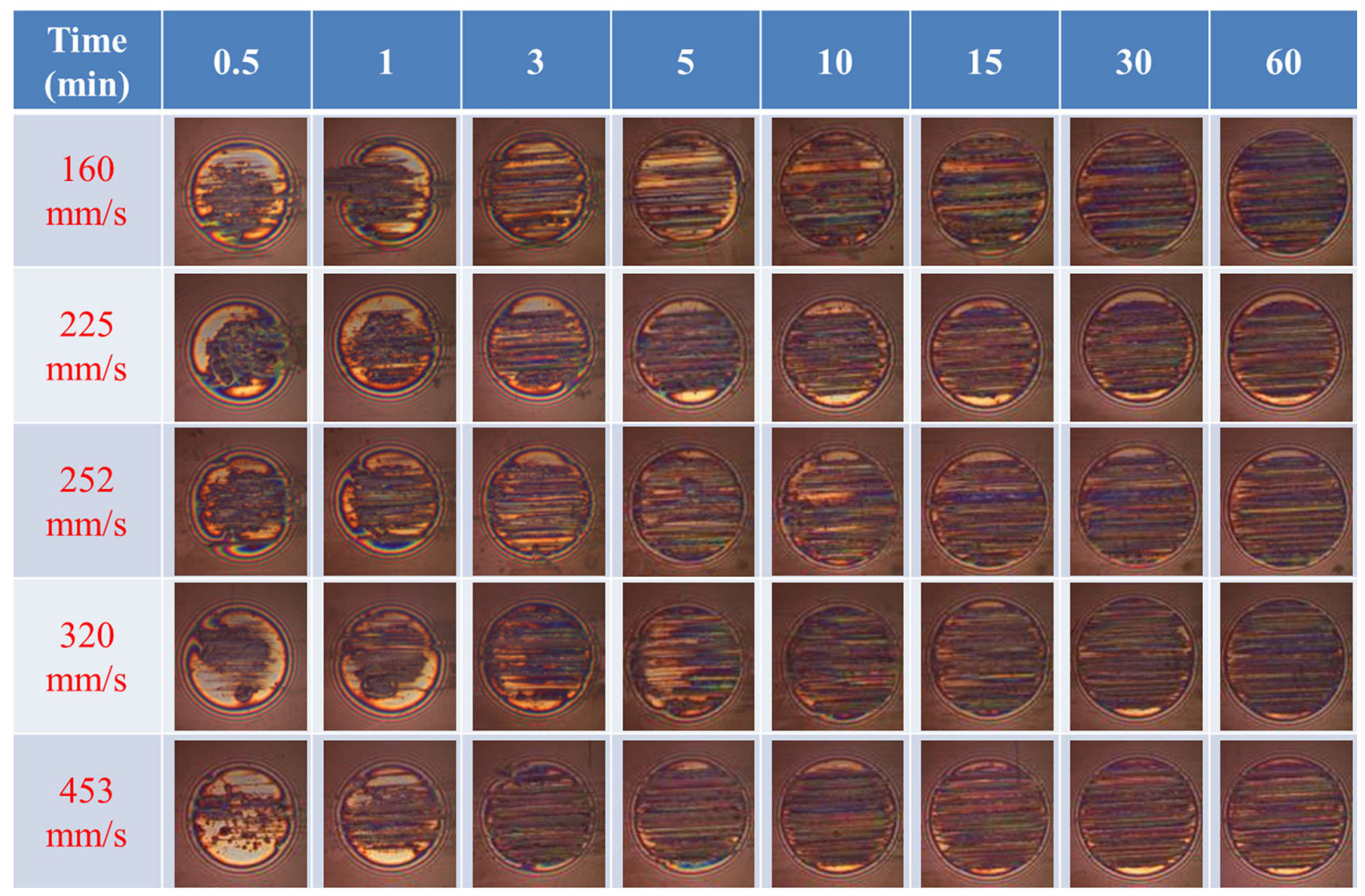

Fig. 13 Series of SLIM images of the ball in pure sliding at various sliding speeds 

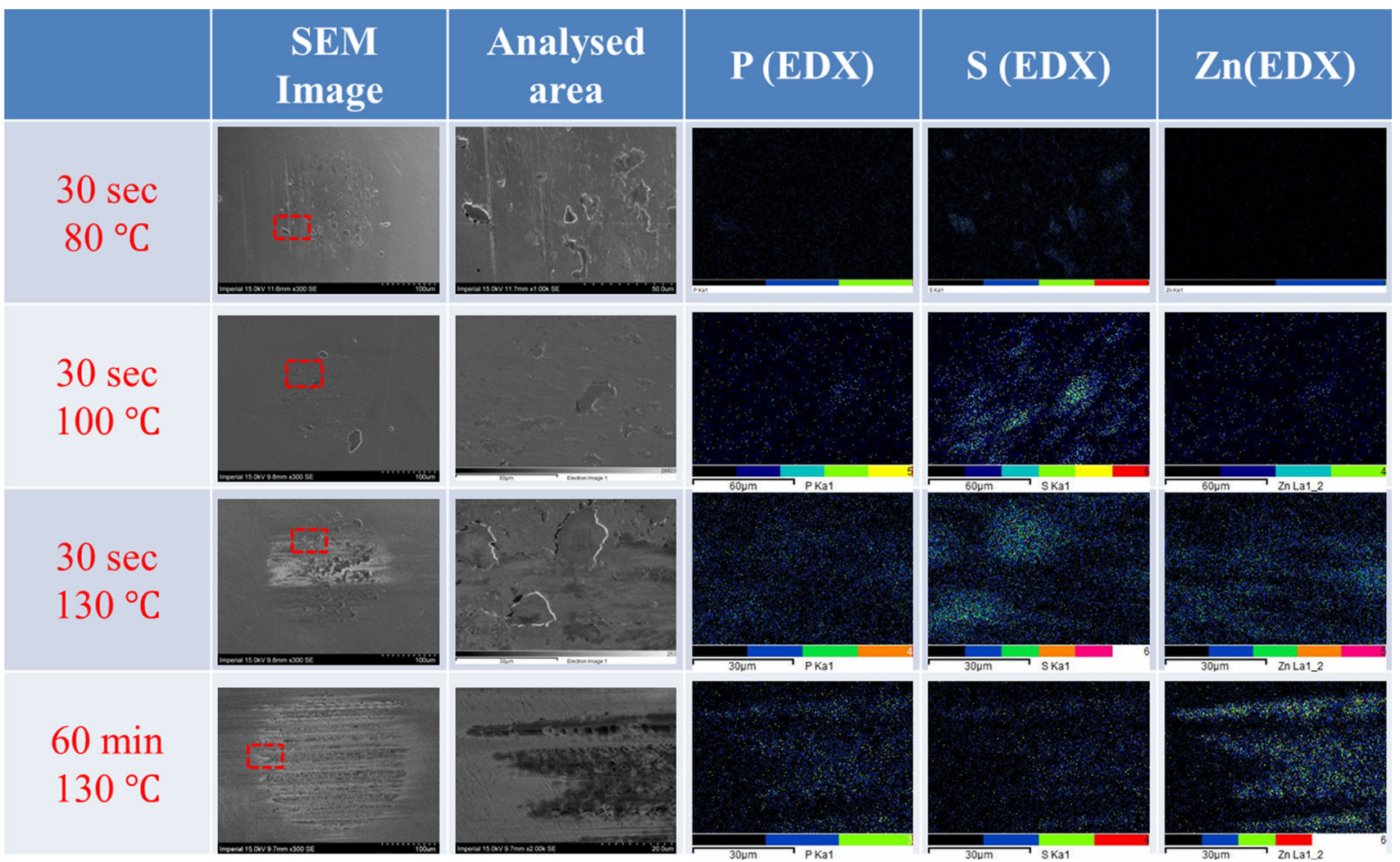

Fig. 14 Intensity results of elements using SEM-EDX

\section{Pure Sliding Conditions}

In pure sliding conditions, the disc is rotating and the ball is stationary. Therefore, tribofilm forms only within an area around the contact point of the ball with the disc. In the SLIM images shown, lubricant enters the contact area from left side and leaves from the right side (Fig. 7).

Contrary to the results in mixed sliding and rolling conditions, in pure sliding ( $200 \%$ SRR) the worn area expanded with test time (Fig. 8). At the beginning of the tests, the diameter of the contact between ball and disc flat was $216 \mu \mathrm{m}$ while the diameter of worn area was approximately $0.22 \mu \mathrm{m}$, which corresponds closely to the theoretically calculated Hertz diameter. However, at 60 min after starting the test, the diameter of the contact between ball and glass window expanded to $0.35 \mathrm{~mm}$ in diameter. This was due to wear of the ball which resulted in an increase in its local radius and thus a larger area of contact between ball and glass window. However, polyalphaolefin base oil with no ZDDP gave much larger contact diameters as illustrated in Fig. 9, showing that ZDDP was still providing some anti-wear performance by limiting the growth of the scar. ZDDP tribofilm was built up over the entire contact area and was created immediately after the start of the test and then remained constant.

In order to confirm the size of wear scar on the ball surface, ZDDP films were removed using a solution of ethylene diamine tetraacetic acid (EDTA) (and its disodium salt) $[13,19]$. A droplet of EDTA sodium salt solution in distilled water was dropped on the ball wear track or scar using a micropipette and wiped away with a paper tissue after a set time. Figure 10 shows the SLIM images captured before and after ZDDP film removal using the EDTA technique. At $100 \%$ SRR, the area where ZDDP film was removed is clearly seen within the rubbed track and indicates negligible wear. In the pure sliding condition, after the ZDDP film is removed from the whole contact area, many scars can be observed on the removal area. In addition, it can also be seen that the size of the scars is similar to that of the worn area.

\subsection{Effect of Temperature in Pure Sliding Conditions}

Since this method of studying pure sliding conditions was newly introduced and also the behaviour of tribofilm formation under pure sliding showed differences from mixed sliding-rolling conditions, the influence of temperature was also investigated. Figure 11 shows the results of tests performed at lubricant temperatures of 40, 80, 100 and $130{ }^{\circ} \mathrm{C}$. 
After $30 \mathrm{~s}$ from the beginning of the tests at 100 and $130{ }^{\circ} \mathrm{C}$, some particles were observed in the contact area (Fig. 12). In contrast to this, very few particles were observed at 40 and $80{ }^{\circ} \mathrm{C}$. For all test conditions, the ball surfaces became damaged and the worn area expanded with test time. However, after $60 \mathrm{~min}$ at 80 and $100{ }^{\circ} \mathrm{C}$, the worn areas were smaller than those observed at $130{ }^{\circ} \mathrm{C}$. It can be concluded that the test temperature affects both the ZDDP tribofilm formation and the anti-wear performance.

\subsection{Effect of Speed in Pure Sliding Conditions}

Figure 13 shows the results of tests performed at 160, 225, 252, 320 and $453 \mathrm{~mm} / \mathrm{s}$ disc speed and $130{ }^{\circ} \mathrm{C}$. At the beginning of all tests, some particles are observed in the contact region and also in the inlet of the contact area. During the tests, these were then removed from the surface and after that the ball surface became damaged and the worn area expanded with test time. From these results, there is no significant influence of disc speed on anti-wear performance and ZDDP film formation.

\subsection{SEM-EDX Results}

Some particles present just after the beginning of the tests in pure sliding conditions, and also the contact area after $60 \mathrm{~min}$, were analysed using SEM-EDX (SEM and EDX) (Fig. 14). A SEM, HITACHI S-3400 N, was used to capture high-resolution images of tribofilm surface topography, and EDX, Oxford X-ray System INCA, was used to analyse the chemical properties of tribofilms. In this study, an accelerating voltage was $15 \mathrm{keV}$ and a working distance was $10 \pm 1 \mathrm{~mm}$.
At $30 \mathrm{~s}$ after the tests started at 80,100 and $130{ }^{\circ} \mathrm{C}$, solid particles were observed on the ball surfaces. EDX analysis showed the presence of $\mathrm{S}$ in the solid particles, and the $\mathrm{S}$ intensity was stronger than those of $\mathrm{P}$ and $\mathrm{Zn}$. In addition, the chemical intensities were stronger as the test temperature increased. However, after $60 \mathrm{~min}$ at $130{ }^{\circ} \mathrm{C}$, a paste-like substance was observed, and the ratio of intensities changed; the $\mathrm{P}$ and $\mathrm{Zn}$ now showed the stronger intensities. From these results, it can be concluded that two different types of tribofilm are created sequentially, displaying different properties depending on the time of rubbing (early and later stage). In other words, a S-rich tribofilm is created initially on the steel ball surface and this is then replaced and/or covered with a $\mathrm{P}$-and $\mathrm{Zn}$-rich tribofilm.

\section{AFM Results}

In order to measure the thickness of ZDDP tribofilm, AFM was used to study the same area of MTM ball surface as that analysed chemically using SEM-EDX. In this study, the apparatus was a WITec alpha 300A and the cantilever was a WITec AFM Arrow Cantilever Reflex-Coated. Figure 15 shows an AFM image of the tribofilm formed after $30 \mathrm{~s}$ rubbing at $130{ }^{\circ} \mathrm{C}$. The two solid particles shown are more than $300 \mathrm{~nm}$ thick and 15 and $20 \mu \mathrm{m}$ in width. Since the two particles showed strong $S$ intensity in Fig. 14, it can be inferred that the two particles are predominantly $\mathrm{S}$-containing material (as compared to $\mathrm{Zn}$ and/or P). These particles are not seen after 60 min rubbing, so they must have been removed or comminuted. They are also not seen in mixed sliding-rolling where the film does not exceed ca $200 \mathrm{~nm}$ regardless of the rubbing time [10, 17].
Fig. 15 Initial film thicknesses measured using AFM

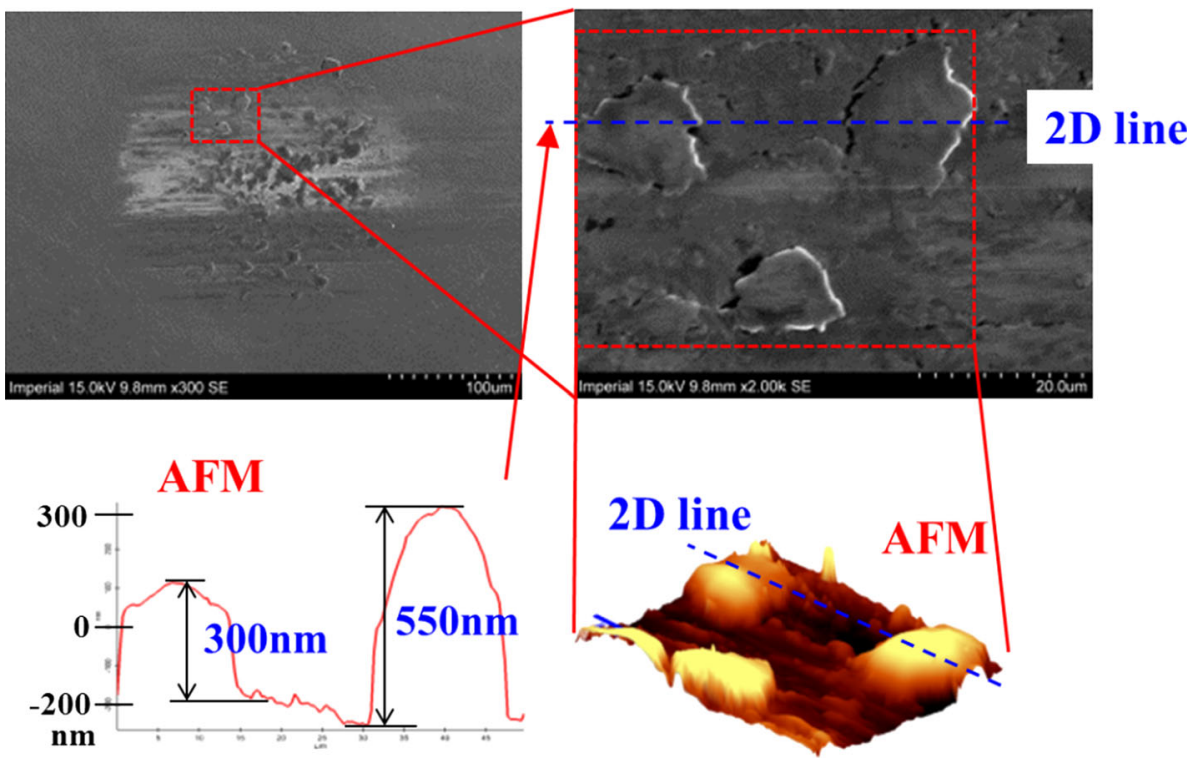




\begin{tabular}{|c|c|c|c|c|c|c|c|c|c|}
\hline $\begin{array}{l}\text { Time } \\
\text { (min) }\end{array}$ & 0.5 & 1 & 3 & 5 & 10 & 15 & 30 & 60 & 90 \\
\hline $200 \%$ & $\mathrm{E} \mathrm{s}$ & & & & & & & $\Leftrightarrow$ & \\
\hline
\end{tabular}

Fig. 16 Series of SLIM images of the balls, S-based additive

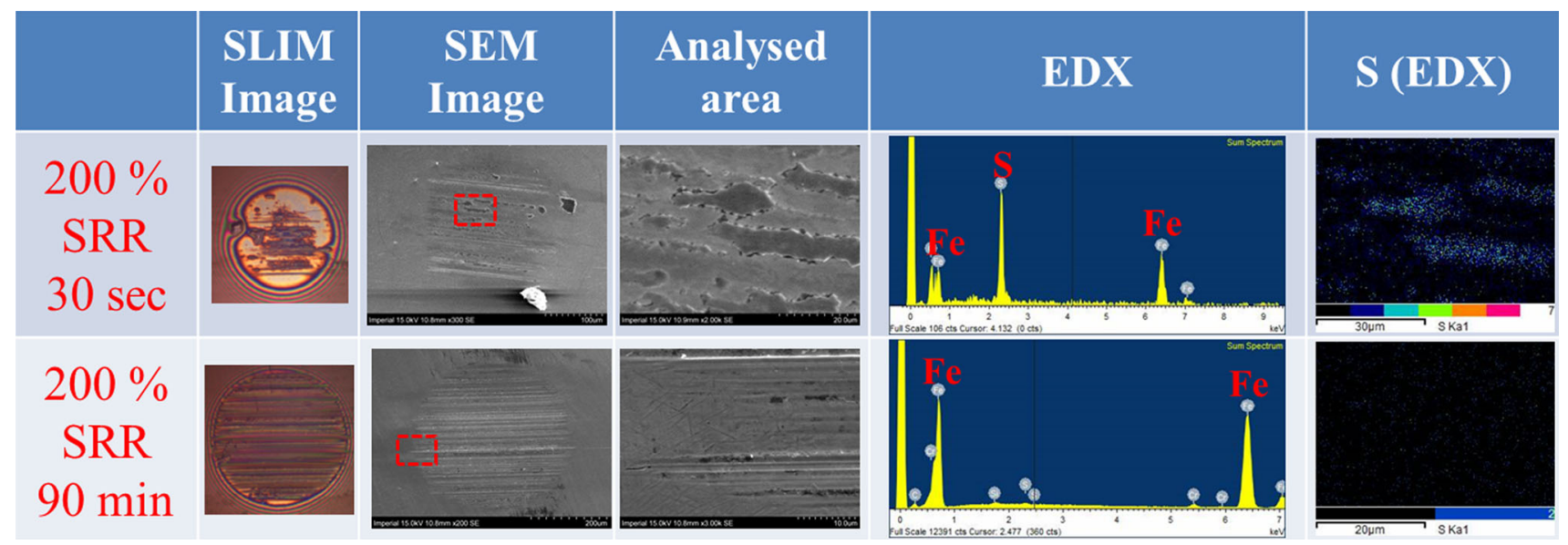

Fig. 17 Intensity results of elements using SEM-EDX, S-based additive

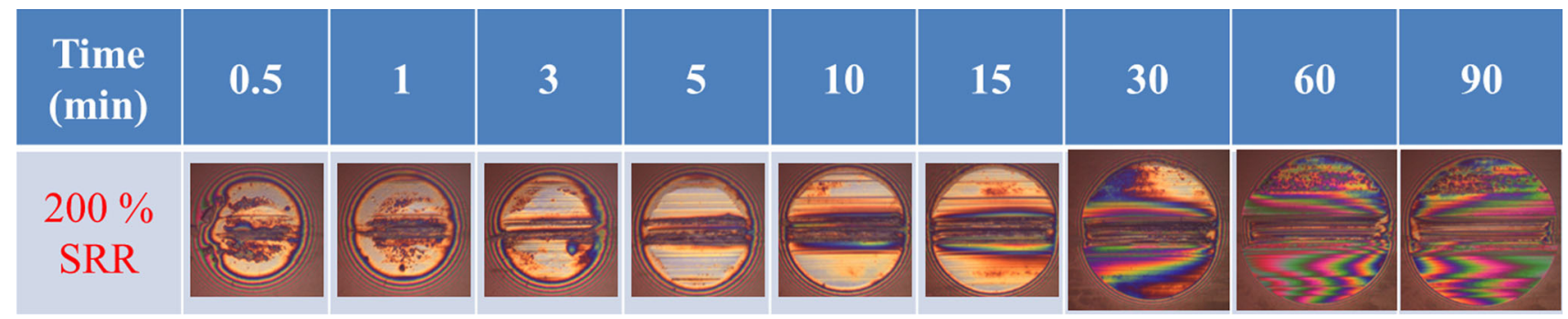

Fig. 18 Series of SLIM images of the balls, P-based additive

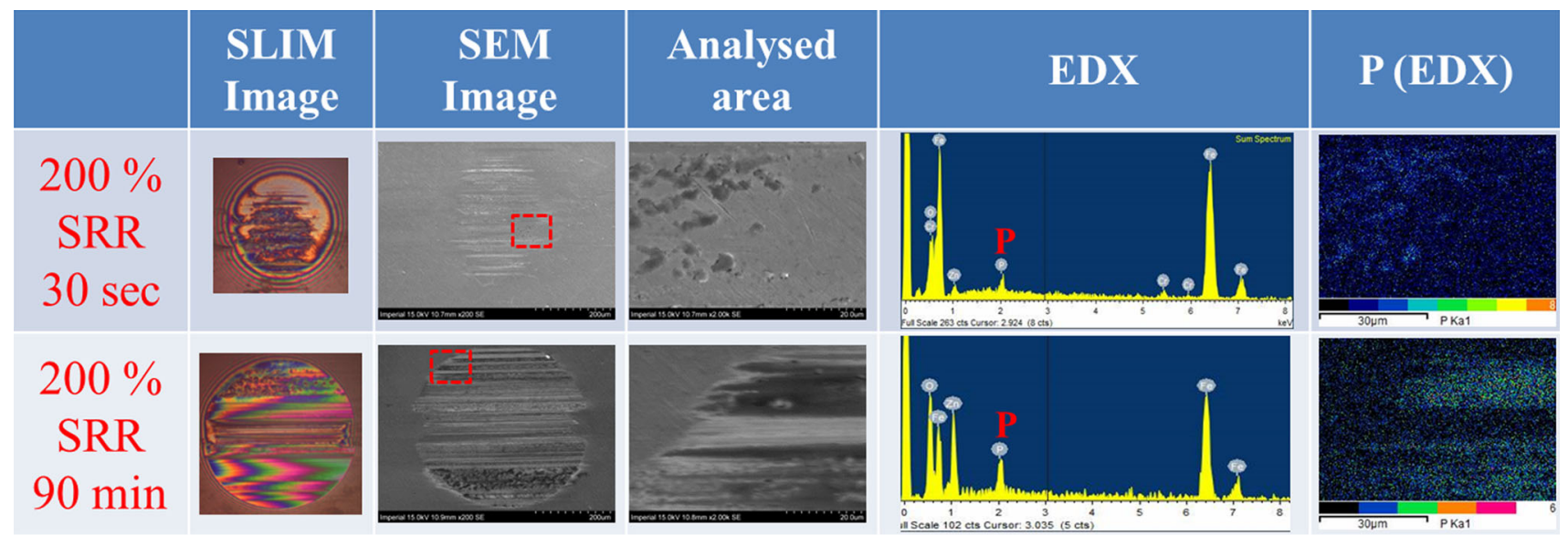

Fig. 19 Intensity results of elements using SEM-EDX, P-based additive 
One possible reason for the different behaviour in pure sliding may be that S-rich tribofilm can form before a P-rich tribofilm develops because of the continuous severe sliding that the small ball contact area experiences in the absence of a phosphorus-based film.

\subsection{Tribofilm Formation Using Non-ZDDP Additives}

The results using ZDDP in pure sliding suggest that a S-rich tribofilm is built up very rapidly on the surface in continuous contact during the initial stage of rubbing, and then a $\mathrm{P}$ - and $\mathrm{Zn}$-containing tribofilm is formed much more slowly. In this study, tribofilm formation was further investigated using a sulphur-based additive and a phosphorus-based additive.

Figures 16 and 17 show the results under a pure sliding condition using the sulphur-based additive. From the MTM-SLIM result, some solid particles are observed at the beginning of the test, and also $S$ was detected on the particles by EDX analysis. However, the $\mathrm{S}$ tribofilm was removed after $5 \mathrm{~min}$ and the worn area expanded with test time. At 90 min, S was not detected on the surfaces. This initial behaviour is similar to the ZDDP results.

Figures 18 and 19 show the results using a phosphorusbased additive. From the MTM-SLIM result, some solid particles are observed at the beginning of the test, and also the worn area expands with time similar to the sulphur additive. However, in contrast to the sulphur additive, the phosphorus tribofilm builds up throughout the test, as indicated by phosphorus being detected at both the 30-s and 90-min stages.

\section{Conclusion}

The authors have developed a new approach to study ZDDP tribofilm formation in pure sliding conditions based on the MTM-SLIM method. Key conclusions are as follows.

1. In mixed sliding-rolling conditions, tribofilm formation occurs at a similar rate over a very wide range of SRR conditions. This suggests that the film formation rate depends on the rubbing time experienced by the surfaces rather than the rubbing distance.

2. In order to build up ZDDP tribofilms without any damage to the surfaces, it is essential to avoid pure sliding conditions; i.e. to move both surfaces with respect to the contact with a minimum speed, even if the two surfaces move in opposite directions (contrarotating mixed sliding-rolling).
3. In pure sliding conditions using ZDDP, even though the worn area on the stationary surface expands with time, tribofilms are still built up during rubbing. These tribofilms initially have a high concentration of $\mathrm{S}$ but after further rubbing a film with a high concentration of $\mathrm{Zn}$ and $\mathrm{P}$ is formed.

4. In the results using a sulphur-based additive under the pure sliding condition, a S-based tribofilm forms almost immediately, similar to ZDDP. This $\mathrm{S}$ tribofilm was removed during the test as it was with ZDDP.

5. In the results using the phosphorus-based additive under the pure sliding condition, the worn area expands with time. However, tribofilms are built up throughout the test, showing similarity to the results using ZDDP.

In most previous research on ZDDP tribofilm formation which has been carried out in mixed sliding-rolling conditions, attention was focussed on the thick glassy Fe phosphate and Zn phosphate layers that develop during prolonged rubbing. This study has shown that in the more severe conditions of pure sliding, a sulphur-rich tribofilm is initially formed and the phosphate-based layer develops later. Such behaviour is suggestive of the well-known dual role of ZDDP as an extreme pressure (EP) and anti-wear additive, with its sulphur content providing EP response under severe conditions and the phosphorus content delivering anti-wear protection under milder, more extended rubbing conditions.

Open Access This article is distributed under the terms of the Creative Commons Attribution 4.0 International License (http://crea tivecommons.org/licenses/by/4.0/), which permits unrestricted use, distribution, and reproduction in any medium, provided you give appropriate credit to the original author(s) and the source, provide a link to the Creative Commons license, and indicate if changes were made.

\section{References}

1. Minfray, C., Martin, J.M., De Barros, M.I., Mogne, T.L., Kersting, R., Hagenhoff, B.: Chemistry of ZDDP tribofilm by ToFSIMS. Tribol. Lett. 17, 351-357 (2004)

2. Martin, J.M., Grossiord, C., Mogne, T.L., Bec, S., Tonck, A.: The two-layer structure of Zndtp tribofilms: part I: AES XPS and XANES analyses. Tribol. Inter. 34, 523-530 (2001)

3. Varlot, K., Kasrai, M., Martin, J.M., Vacher, B., Bancroft, G.M., Yamaguchi, E.S., Ryason, P.R.: Antiwear film formation of neutral and basic ZDDP: influence of the reaction temperature and of the concentration. Tribol. Lett. 8, 9-16 (2000)

4. Zhang, Z., Yamaguchi, E.S., Kasrai, M., Bancroft, G.M., Liu, X., Fleet, M.E.: Tribofilms generated from ZDDP and DDP on steel surfaces: part 2, chemistry. Tribol. Lett. 19, 221-229 (2005)

5. Aktary, M., McDermott, M.T., McAlpine, G.A.: Morphology and nanomechanical properties of ZDDP antiwear films as a function of tribological contact time. Tribol. Lett. 12, 155-162 (2002)

6. Minfray, C., Martin, J.M., Esnouf, C., Le Mogne, T., Kersting, R., Hagenhoff, B.: A multi-technique approach of tribofilm characterisation. Thin Solid Films 447, 272-277 (2004) 
7. Li, Y.R., Pereira, G., Lachenwitzer, A., Kasrai, M., Norton, P.R.: Studies on ZDDP thermal film formation by XANES spectroscopy, atomic force microscopy, FIB/SEM and 31P NMR. Tribol. Lett. 29, 11-22 (2008)

8. Spikes, H.A., Cann, P.M.: The development and application of the spacer layer imaging method for measuring lubricant film thickness. Proc. Inst. Mech. Eng. Part J J. Eng. Tribol. 215, 261-277 (2001)

9. Taylor, L., Dratva, A., Spikes, H.A.: Friction and wear behavior of Zinc dialkyldithiophosphate additive. Tribol. Trans. 43, 469-479 (2000)

10. Fujita, H., Spikes, H.A.: The formation of zinc dithiophosphate antiwear films. Proc. Inst. Mech. Eng. Part J: J. Eng. Tribol. 218, 265-278 (2004)

11. Fujita, H., Glovnea, R.P., Spikes, H.A.: Study of zinc dialkydithiophosphate antiwear film formation and removal processes, part I: experimental. Tribol. Trans. 48, 558-566 (2005)

12. Fujita, H., Spikes, H.A.: Study of zinc dialkyldithiophosphate antiwear film formation and removal processes, part II: kinetic model. Tribol. Trans. 48, 567-575 (2005)

13. Ksenija, T.M., Forbus, T.R., Spikes, H.A.: Film thickness and roughness of ZDDP antiwear films. Tribol. Lett. 26, 161-171 (2007)
14. Matthew, S., Hamer, C., Spikes, H.A.: A study of antiwear additive film build up using the MTM (mini-traction machine). ASME/STLE 2007 International Joint Tribology Conference. American Society of Mechanical Engineers (2007)

15. Miklozic, K.T., Forbus, T.R., Spikes, H.A.: Performance of friction modifiers on ZDDP generated surfaces. Tribol. Trans. 50, 328-335 (2007)

16. Olomolehin, Y., Kapadia, R., Spikes, H.: Antagonistic interaction of antiwear additives and carbon black. Tribol. Lett. 37, 49-58 (2010)

17. Zhang, J., Yamaguchi, E., Spikes, H.: The antagonism between succinimide dispersants and a secondary zinc dialkyl dithiophosphate. Tribol. Trans. 57, 57-65 (2014)

18. Zhang, J., Spikes, H.: On the mechanism of ZDDP antiwear film formation. Tribol. Lett. 63, 24 (2016)

19. Benedet, J., Green, J.H., Lamb, G.D., Spikes, H.A.: Spurious mild wear measurement using white light interference microscopy in the presence of antiwear films. Tribol. Trans. 52, 841-846 (2009) 